\title{
Early and late mortality in patients undergoing transcatheter aortic valve implantation: Comparison of the Novel EuroScore II with established risk scores
}

\author{
Stähli, Barbara E ; Tasnady, Hanna ; Lüscher, Thomas F ; Gebhard, Cathérine ; Mikulicic, Fran ; \\ Erhart, Ladina ; Bühler, Ines ; Landmesser, Ulf ; Altwegg, Lukas ; Wischnewsky, Manfred B ; \\ Grünenfelder, Jürg ; Falk, Volkmar ; Corti, Roberto ; Maier, Willibald
}

\begin{abstract}
Objectives: In the evaluation of patients considered for transcatheter aortic valve implantation (TAVI), the EuroScore II might be superior to established risk scores. Methods: We assessed the performance of the EuroScore II in predicting mortality in a cohort of 350 TAVI patients. Results: The EuroScore II and the logistic EuroScore were higher in nonsurvivors compared to survivors at 30 days $(12.6 \pm 1.8$ vs. $7.5 \pm 0.3 \%, \mathrm{p}<0.001$ for EuroScore II, and $27.7 \pm 2.8$ vs. $22.1 \pm 0.8 \%, \mathrm{p}=0.04$ for logistic EuroScore), while the STS-PROM score did not differ $(7.3 \pm 0.8$ vs. $6.4 \pm 0.3 \%, p=0.09)$. The area under the curve (AUC) was 0.70 for the EuroScore II, 0.61 for the logistic EuroScore and 0.59 for the STS-PROM score for predicting 30-day mortality. Based on the estimated 30-day mortality risk, 3 risk groups were identified, a low-risk (EuroScore II 4\%, 30-day mortality 1.2\%), an intermediate-risk (EuroScore II between $4 \%$ and 9\%, 30-day mortality 8.6\%) and a high-risk group (EuroScore II >9\%, 30-day mortality, $17.1 \%$; $=0.03$ ). Regarding cumulative mortality, the AUC was 0.67 for the EuroScore II, 0.62 for the logistic EuroScore and 0.55 for the STS-PROM score for predicting mortality at total follow-up. Conclusions: In this patient cohort, the EuroScore II performed best in predicting short- and long-term mortality.
\end{abstract}

DOI: https://doi.org/10.1159/000351438

Posted at the Zurich Open Repository and Archive, University of Zurich

ZORA URL: https://doi.org/10.5167/uzh-82047

Journal Article

Accepted Version

Originally published at:

Stähli, Barbara E; Tasnady, Hanna; Lüscher, Thomas F; Gebhard, Cathérine; Mikulicic, Fran; Erhart, Ladina; Bühler, Ines; Landmesser, Ulf; Altwegg, Lukas; Wischnewsky, Manfred B; Grünenfelder, Jürg; Falk, Volkmar; Corti, Roberto; Maier, Willibald (2013). Early and late mortality in patients undergoing transcatheter aortic valve implantation: Comparison of the Novel EuroScore II with established risk scores. Cardiology, 126(1):15-23.

DOI: https://doi.org/10.1159/000351438 
Zurich, April $9^{\text {th }}, 2013$

\section{Early and Late Mortality in Patients Undergoing Transcatheter Aortic Valve Implantation (TAVI): Comparison of the Novel EuroScore II with Established Risk Scores}

\section{Running Head: Risk Scores in TAVI Patients}

Barbara E. Stähli ${ }^{1}$, MD; Hanna Tasnady ${ }^{1}$, BSc; Thomas F. Lüscher ${ }^{1}$, MD; Cathérine Gebhard ${ }^{1}$, MD; Fran Mikulicic ${ }^{1}$, MD; Ladina Erhart ${ }^{1}$, BSc; Ines Bühler ${ }^{1}$; Ulf Landmesser ${ }^{1}$, MD; Lukas Altwegg ${ }^{1}$, MD; Manfred B. Wischnewsky ${ }^{3}$, PhD; Jürg Grünenfelder ${ }^{2}$, MD; Volkmar Falk ${ }^{2}$, MD; Roberto Corti ${ }^{1}$, MD; Willibald Maier ${ }^{1}, M D$

University Heart Center, 'Department of Cardiology and ${ }^{2}$ Departement of Cardiovascular Surgery, University Hospital Zürich, Switzerland

${ }^{3}$ FB Mathematics and Computer Science, University of Bremen, Germany

Address for correspondence:

Willibald Maier, MD

Department of Cardiology, University Heart Center Zurich, University Hospital Zürich

Rämistrasse 100, 8091 Zürich, Switzerland

Phone: +41-44-255 85 71, Fax: +41-44-255 4401

E-mail:karmaiew@usz.uzh.ch 


\section{KEY WORDS}

Risk Scoring System, Aortic Stenosis, Transcatheter Aortic Valve Implantation 


\begin{abstract}
Objectives: In the evaluation of patients considered for transcatheter aortic valve implantation (TAVI), the EuroScore II might be superior to established risk scores.

Methods: We assessed the performance of the EuroScore II in predicting mortality in a cohort of 350 TAVI patients.

Results: The EuroScore II and the logistic EuroScore were higher in non-survivors compared to survivors at 30 days $(12.6 \pm 1.8$ vs. $7.5 \pm 0.3, p<0.001$ for the EuroScore II; and $27.7 \pm 2.8$ vs. $22.1 \pm 0.8$, $p=0.04$ for the logistic EuroScore), while the STS-PROM score did not differ $(7.3 \pm 0.8$ vs. $6.4 \pm 0.3$, $\mathrm{p}=0.09$ ). The AUC was 0.70 for the EuroScore II, 0.61 for the logistic EuroScore, and 0.59 for the STS-PROM score for predicting 30-day mortality. Based on the estimated 30-day mortality risk, 3 risk groups were identified, a low-risk (EuroScore II $\leq 4 \%$, 30-day mortality $1.2 \%$ ), an intermediate risk (EuroScore II between 4\% and 9\%, 30-day mortality 8.6\%), and a high-risk group (EuroScore II $>9 \%, 30$-day mortality, $17.1 \% ; p=0.03)$. Regarding cumulative mortality, the AUC was 0.67 for the EuroScore II, 0.62 for the logistic EuroScore, and 0.55 for the STS-PROM score for predicting mortality at total follow-up.
\end{abstract}

Conclusions: In this patient cohort, the EuroScore II performed best in predicting short- and longterm mortality. 


\section{INTRODUCTION}

Degenerative aortic stenosis (AS) is the most common valvular heart disease in Western communities and is continuously increasing in the aging population.[1] Without intervention, symptomatic AS has a poor outcome with an average survival of less than 4 years.[2] Until recently, surgical aortic valve replacement (AVR) has been considered as standard treatment for such patients.[2,3] However, for patients not referred to open-heart surgery due to advanced age, severe comorbidities, or an expected high operative mortality, transcatheter aortic valve implantation (TAVI) has become a less-invasive treatment alternative.[2,4-6]

To predict morbidity and mortality after surgical procedures, different risk scoring algorithms based on both patient history and functional status have been established. The most widely applied risk scoring systems are the logistic European System for Cardiac Operative Risk Evaluation (EuroScore) and the Society of Thoracic Surgeons predicted risk of mortality (STS-PROM) score. A novel version of the EuroScore, the EuroScore II, has recently been developed as the logistic EuroScore was known to overestimate mortality rates, in particular in high-risk patients.[7-10] In patients undergoing AVR, the STS score has been shown to better predict mortality compared to the logistic EuroScore.[11,12] In addition to these well-established risk algorithms, several other risk scoring systems such as the Cleveland Clinic Score or the Australian risk prediction model have been proposed as risk models in patients with valvular or coronary heart disease.[13-16]

In the era of TAVI, it is of particular importance to identify patients with severe AS at high surgical risk, who may benefit from this treatment. Accordingly, different risk algorithms are commonly used in addition to a comprehensive clinical risk stratification of an individual patient. TAVI is currently recommended for high-risk or inoperable patients including those with surgical contraindications, severe comorbidities or increased surgical risk.[17] However, the reliability of the established risk algorithms in patients evaluated for TAVI has recently been questioned. Neither the logistic EuroScore, nor the STS-PROM score or the EuroScore II have been validated to specifically predict mortality after TAVI. Despite the wide use of these risk scores in the context of TAVI, there is little data on the performance of the revisited EuroScore II in comparison to the established risk models, i.e. the logistic EuroScore and the STS-PROM score. Indeed, prediction of mortality rates in patients evaluated for TAVI differs considerably among different scoring systems with conflicting results among different studies. In transapically treated patients, the study by Haensig et al showed that the 
STS-PROM score was a better predictor of 30-day mortality than the new EuroScore II, while another study did not confirm these results.[18,19] In two most recent studies including both transapically and transfemorally treated patients, the EuroScore II tended to perform better with regard to discriminatory power compared to the logistic EuroScore and the STS-PROM score, in particular in the transfemorally treated patient cohort.[20,21]

The aim of this study was to further characterize the performance of the EuroScore II in comparison to the logistic EuroScore and the STS-PROM score in a larger TAVI population with regard to both, early and late mortality, and to delineate different EuroScore II risk categories (low risk, intermediate risk, an high risk) with respect to survival after TAVI. 


\section{METHODS}

\section{Patients and Procedures}

The present study included 350 patients with severe AS (mean transaortic systolic pressure gradient of $\geq 40 \mathrm{mmHg}$, or an aortic valve area of $<1.0 \mathrm{~cm}^{2}$ or $<0.6 \mathrm{~cm}^{2} / \mathrm{m}^{2}$ ) undergoing TAVI at the University Hospital Zurich, Switzerland. All patients were evaluated for TAVI by a multidisciplinary board of interventional cardiologists, cardiac surgeons, cardiac anaesthesiologists, and imaging specialists (i.e. a Heart Team). ${ }^{11}$ In all patients, comprehensive clinical assessment, transthoracic and transesophageal echocardiography, coronary angiography, and multislice computed tomography were performed before the procedure. The procedure was performed in the cardiac catheterization laboratory or the hybrid operation room. Procedural details have previously been reported.[22] In 341 patients, the procedure was performed under general anesthesia, and in 9 patients it was done under local anesthesia, respectively. The Medtronic CoreValve (26, 29, $31 \mathrm{~mm})$, the Edwards SAPIEN (23, 26, and $29 \mathrm{~mm})$, and the Medtronic Engager (26mm) prostheses were utilized.

All scores were calculated online using the official websites and calculators (logistic EuroScore: http://euroscore.org/calcold.html; EuroScore II: http://euroscore.org/calc.html; STS-PROM score: http://riskcalc.sts.org/STSWebRiskCalc273/de.aspx). The study was approved by the local ethical committee. Written informed consent was obtained from all patients.

\section{Statistical Analysis}

Continuous variables are presented as means \pm standard error, or medians and interquartile range, as appropriate. Categorical variables are given as frequencies and percentages. Prognostic results are the numbers of events that occur over time. They were expressed (1) in absolute terms (e.g. 30day mortality rates), (2) in relative terms (e.g. risk from prognostic scores), and (3) in survival curves (cumulative events over time). Continuous variables were tested for differences with ANOVA or Mann-Whitney/Kruskal-Wallis test, as appropriate. Categorical variables were tested by the Pearson's $\mathrm{x} 2$ test or the Fisher's exact test as appropriate. Correlation analysis of different scores was performed using the Spearman's correlation coefficient. Discriminatory power was assessed by receiver-operation characteristic $(R O C)$ curve evaluation and the area under the curve (AUC) accompanied by $95 \%$ confidence intervals $(\mathrm{Cl})$. Calibration, comparing the observed and the predicted probabilities for equal-sized quantiles of risk, was evaluated by the Hosmer-Lemeshow 
goodness-of-fit test. Cut-points were calculated using exhausted Chi-squared Automatic Interaction Detection (exhausted CHAID), a type of decision tree technique, based upon adjusted significance testing (Bonferroni testing). The Cox proportional hazards model was used to estimate the hazard ratio and confidence intervals respectively to adjust for differing risk factor distributions between groups. A two-sided $P$-value of $<0.05$ was considered statistical significant. All statistical analyses were performed using IBM-SPSS version 20 (IBM Corp.) and R 2.15 for Windows. 


\section{RESULTS}

\section{Patient characteristics}

Mean age was $82.2 \pm 7.1$ years. Sex was equally distributed $(48.9 \%$ male). Transfemoral procedures were performed in $83 \%(n=289)$ patients, transapical procedures in $17 \%(n=61)$, respectively. The CoreValve prosthesis was used in $65 \%(n=189)$ of the patients, the Edwards SAPIEN prosthesis in $45 \%(n=158)$, and the Medtronic Engager prosthesis in $1 \%(n=3)$ of the patients, respectively. Patients were at high surgical risk as expressed by a mean EuroScore II of $8.0 \pm 0.3 \%$, a mean logistic EuroScore of $22.6 \pm 0.7 \%$, and mean STS-PROM score of $6.5 \pm 0.3 \%$.

In patients treated with an Edwards SAPIEN prosthesis, mean EuroScore II was $8.3 \pm 0.6 \%$, mean logistic EuroScore $22.5 \pm 1.1 \%$, and mean STS-PROM score $6.6 \pm 10.4 \%$, respectively. In patients treated with a Medtronic CoreValve prosthesis, mean EuroScore II was $7.7 \pm 0.4 \%$, mean logistic EuroScore $22.7 \pm 1.0 \%$, and mean STS-PROM score $6.4 \pm 0.4 \%$. For all three scores, there were no significant differences between the two prosthesis types ( $(p=0.85$ for the logistic EuroScore, $p=0.87$ for the EuroScore II, and $\mathrm{p}=0.80$ for the STS-PROM score, respectively).

Half of the patients (i.e. $49.7 \%$ or $174 / 350$ ) had a logistic EuroScore $>20 \%$, and $14.6 \%(51 / 350)$ a STS-PROM score $>10 \%$. Patient characteristics are summarized in Table 1.

\section{Predicted versus observed mortality at 30 days}

Thirty day all-cause mortality was $9.1 \%$ without any significant difference between access sites $(14.8 \%$ in transapically treated patients vs. $8.0 \%$ in transfemorally treated patients, $p=0.09)$ and prosthesis types $(7.0 \%$ in patients treated with an Edwards SAPIEN prosthesis vs. $10.5 \%$ in patients treated with a Medtronic CoreValve prosthesis, $\mathrm{p}=0.18$ ).

Regarding risk score quartiles, the logistic EuroScore overestimated mortality, in particular in highrisk patients where mortality was overestimated by a factor 3.3. The STS-PROM score underestimated mortality, in particular in low-risk patients where mortality was 2.5 times higher than predicted (Table 2). The EuroScore II and the logistic EuroScore were significantly higher in patients who died within the first 30 days after the procedure compared to those who survived $(12.6 \pm 1.8 \%$ vs. $7.5 \pm 0.3 \%, p<0.001$ for the EuroScore II, Figure $1 \mathrm{~A}$; and $27.7 \pm 2.8 \%$ vs. $22.1 \pm 0.8 \%, p=0.04$ for the logistic EuroScore, Figure 1B; respectively). The STS-PROM score did not differ between nonsurvivors and survivors at 30 days $(7.3 \pm 0.8 \%$ vs. $6.4 \pm 0.3 \%, p=0.09$, Figure $1 C)$. 
All-cause mortality at 30 days was $12.0 \%$ in the first half of patients, and $6.3 \%$ in the second half $(p=0.07)$ reflecting the learning curve of the operators. In patients treated with an Edwards SAPIEN prosthesis, all-cause mortality at 30 days was $9.1 \%$ in the first half and $4.9 \%$ in the second half of patients $(p=0.31)$, and in those treated with a Medtronic CoreValve prosthesis, it was $13.7 \%$ in the first and $7.4 \%$ in the second half $(p=0.16)$, respectively. There was no significant difference with regard to all-cause 30 -day mortality between prosthesis types $(p=0.35$ in the first, and $p=0.50$ in the second half of patients, respectively).

Both logistic EuroScore as well as EuroScore II were significantly higher in the first half of patients compared to the second half $(24.3 \pm 1.1$ vs. $21.0 \pm 1.0, p=0.009$ for the logistic EuroScore; and $10.0 \pm 0.6$ vs. $6.0 \pm 0.3$ for the EuroScore II, $p<0.001$ ), while, in contrast, the STS-PROM score was lower in the first half of patients $(5.7 \pm 0.3$ vs. $7.3 \pm 0.5, p=0.02)$.

Patients with a reduced left ventricular ejection fraction (LVEF) $<35 \%$ had a higher observed 30 day mortality compared to those with a LVEF > 35\% (17.9\% vs. $7.7 \%, p=0.03)$. In patients with a LVEF $<35 \%$ both, the EuroScore II as well as the logistic EuroScore, were higher compared to patients with a LVEF $>35 \%(13.1 \pm 1.5 \%$ vs. $7.3 \pm 0.3 \%, p<0.001$ for the EuroScore II; and $37.5 \pm 2.8 \%$ vs $20.4 \pm 0.7 \%, p<0.001$ for the logistic EuroScore,respectively). The STS-PROM score did not differ significantly between patients with a LVEF $<35 \%$ and those with a LVEF $>35 \% \quad(7.2 \pm 0.8 \%$ vs. $6.2 \pm 0.3 \%, p=0.29)$.

\section{Risk score performance in predicting 30-day mortality}

Spearman's correlation coefficient revealed a moderate correlation between the EuroScore II and the logistic EuroScore $(r=0.59, p<0001)$, while both the EuroScore II and the logistic EuroScore only weakly correlated with the STS-PROM score $(r=0.30, p<0.001$ for the EuroScore II; and $r=0.32$, $p<0.001$ for the logistic EuroScore, respectively).

ROC curve analysis showed that all three risk scores performed suboptimal in predicting 30-day mortality (Figure 2). The EuroScore II had a better predictive value compared to the logistic EuroScore or the STS-PROM-Score. In ROC analysis, the AUC was $0.70(95 \% \mathrm{Cl} 0.61-0.78$; $\mathrm{p}<0.001)$ for the EuroScore II, $0.61(95 \% \mathrm{Cl} 0.50-0.72 ; \mathrm{p}=0.04)$ for the logistic EuroScore, and 0.59 (95\% $\mathrm{Cl}$ 0.49-0.69; $\mathrm{p}=0.09)$ for the STS-PROM score for predicting 30-day mortality. A cut-off value of $20 \%$ for the logistic EuroScore had a sensitivity of 0.63 and a specificity of 0.52 in predicting 30 day mortality. A cut-off value of $10 \%$ for the STS-PROM Score had a sensitivity of 0.22 and a 
specificity of 0.86 in predicting 30 -day mortality. The Hosmer-Lemeshow test did not show any lack of calibration for all scores. Calibration by Hosmer-Lemeshow Chi square was $10.3(p=0.15)$ for the EuroScore II, $12.1(p=0.25)$ for the logistic EuroScore, and $2.6(p=0.96)$ for the STS-PROM score, respectively.

\section{Risk score performance in predicting cumulative mortality}

Mean follow-up was $410 \pm 22$ days. Regarding cumulative mortality, the EuroScore II and the logistic EuroScore were significantly higher in patients who died compared to those who survived after TAVI (11.2 \pm 1.0 vs. $7.1 \pm 0.3, p<0.001$ for the EuroScore II, Figure $1 \mathrm{D}$; and $27.1 \pm 1.7$ vs. $21.4 \pm 0.8, p=0.001$ for the logistic EuroScore, Figure 1E, respectively). Regarding cumulative mortality, the STS-PROM score did not differ between non-survivors and survivors ( $6.7 \pm 0.5$ vs. $6.5 \pm 0.3, p=0.09$, Figure $1 \mathrm{~F})$. In ROC analysis for predicting cumulative mortality, the AUC was $0.67(95 \% \mathrm{Cl} 0.61-0.74 ; \mathrm{p}<0.001)$ for the EuroScore II, $0.62(95 \% \mathrm{Cl} 0.55-0.69 ; \mathrm{p}=0.001)$ for the logistic EuroScore, and $0.55(95 \% \mathrm{Cl}$ 0.48-0.62; $p=0.19)$ for the STS-PROM score.

\section{Low-risk, intermediate risk, and high-risk TAVI patients based on EuroScore II calculations}

According to calculated optimal cut-points for the EuroScore II, the patient cohort was devided into three groups: a low-risk group with an EuroScore $\mathrm{II} \leq 4 \%$ and a 30 -day mortality rate of $1.2 \%$, an intermediate risk group with an EuroScore II between $4 \%$ and $9 \%$ and a 30 -day mortality rate of $8.6 \%$, and a high-risk group with an EuorScore II > 9\% and a 30-day mortality rate of $17.1 \%(p=0.03$; Figure $3 \mathrm{~A})$. The Cox proportional hazards model was used to estimate the hazard ratio and confidence intervals respectively to adjust for differing risk factor distributions between groups (intermediate risk group: $\mathrm{HR} 2.1,95 \% \mathrm{Cl} 0.99-4.44, \mathrm{p}=0.05$ vs. low-risk group; high-risk group: HR $2.87,95 \% \mathrm{Cl} 1.38-5.97, \mathrm{p}=0.005$ vs. low-risk group; Figure $3 \mathrm{~B})$. 


\section{DISCUSSION}

This study demonstrates that in TAVI patients the EuroScore II outperformed the logistic EuroScore and the STS-PROM score with regard to discriminatory power in predicting all-cause mortality at 30 days as well as over the entire follow-up period. However, all three scores are not ideally suited to predict mortality in these patients. Nevertheless, based on estimated 30-day mortality risk as calculated by the EuroScore II, three groups of different risk of mortality (low risk, intermediate, and high risk, respectively) could be defined.

Despite of the fact that it has been primarily designed for patients considered for major cardiac surgery, in particular coronary artery bypass grafting (CABG), the logistic EuroScore has been widely used in patients evaluated for AVR.[23] However, a progressive loss of calibration of the logistic EuroScore has been observed over time with expected and observed mortalities diverging as both patient risk profiles and operative mortalities changed since its introduction in 1999.[23,24] It is wellknown that in patients evaluated for AVR, the logistic EuroScore overestimates the risk of mortality, in particular in high-risk and in elderly patients.[25] Of note, these patients are potential candidates for transcatheter procedures (TAVI), in which optimal risk prediction for patient selection is particularly important. Previous studies have demonstrated that the logistic EuroScore clearly overerstimated mortality in TAVI patients as well, in particular in those at high risk.[19,25,26] In line with these data, in our TAVI patient cohort, the logistic EuroScore clearly overestimated 30-day mortality, e.g. in particular in patients at high risk by a factor of 3.3. These findings are important, since overestimation of the mortality risk might lead the Heart Team to select TAVI, although AVR still would have been feasible. Of note, current real life registries demonstrate a general trend towards lower risk patients selected for TAVI $[27,28]$; based on our results such patients might be at an even lower risk than suggested by currently used risk scores. More importantly, overestimation of procedural risk might shift potential TAVI candidates to medical management.

In contrast to the logistic EuroScore, the STS-PROM score underestimated the observed 30-day mortality of $9.1 \%$ predicting a 30 -day mortality of $6.5 \%$. In low-risk patients the mortality was 2.5 times higher than predicted. Previous studies have reported similar findings after cardiac surgery. [12] Piazza et al compared the performance of the logistic EuroScore to the STS score in TAVI patients. In line with observations in patients undergoing AVR, the STS score had a better predictive ability than the logistic EuroScore also in TAVI patients.[11,25,29] 
The EuroScore II was recently proposed as an updated version of the logistic EuroScore to improve risk prediction after cardiac surgery. $[8,10,30]$ Variables such as poor mobility, NYHA functional class, and diabetes were incorporated into the new risk model. Different categories of renal impairment, pulmonary hypertension, and LVEF as well as different grades of pulmonary hypertension were included into the risk algorithm. Reduced mobility due to neurological dysfunction or to musculoskeletal dysfunction was also added. Despite these efforts, a multicenter validation

study demonstrated that the EuroScore II did not improve the performance in the higher tertiles of risk in patients undergoing major cardiac surgery.[8,30] Moreover, Chalmers et al recently demonstrated that the EuroScore II failed to improve on the original logistic EuroScore model for isolated AVR and miscellaneous procedures.[31]

Comparing the three scores in TAVI patients, in this patient cohort, the EuroScore II outperformed the two other scores in predicting 30-day mortality with an AUC of 0.70 compared to 0.61 for the logistic EuroScore, and 0.59 for the STS-PROM score, respectively. Moreover, both versions of the EuroScore were significantly different between non-survivors and survivors at 30 days, while the STS-PROM score was not. In line with the usual learning curve for establishing new procedures, mortality tended to be lower in the second half of patients. Interestingly, both versions of the EuroScore were lower in the second half of patients, while contradictory results were obtained for the STS-PROM score. Thus, in particular the STS-PROM score seems to address patient characteristics less well in the TAVI population. Patients with a reduced LVEF are an important subgroup of patients in the population evaluated for TAVI, and this subgroup is known to have an increased risk of mortality after TAVI. Both versions of the EuroScore correctly identified the increased risk of mortality in patients with reduced LVEF, while the STS-PROM score predicted similar 30-day mortality rates for both patient groups. In line with our findings, most recently, two studies compared the performance of the EuroScore II in TAVI patients to the logistic EuroScore and the STS-PROM score with regard to short-term mortality. In both studies, the EuroScore II tended to have a better discriminatory power in 30-day mortality risk prediction compared to the logistic EuroScore, in particular in transfemorally treated patients.[20,21]

Based on the current data from our TAVI patient cohort, a low-risk, an intermediate risk, and a high-risk patient group was defined utilizing the EuroScore II. Patients with EuroScores below 4\% comprised the low-risk group (observed 30 -day mortality of $1.2 \%$ ), those with values between $4 \%$ and $9 \%$ the intermediate risk group (observed 30-day mortality of $8.6 \%$ ), and those with EuroScores 
above $9 \%$ the high-risk group (observed 30 -day mortality of $17.1 \%$ ). In addition to short-term outcome prediction, a subdivision of patients within these three risk groups significantly differentiated cumulative survival after TAVI. The proposed stratification into different risk groups might help in part anticipate expected procedural complications and post-interventional mortality in individual patients evaluated for TAVI. However, risk categories and cut-off values for the EuroScore II need to be evaluated prospectively in large TAVI databases and better refined to further improve the predictive discriminative power of this score which performs still below expectations.

With regard to long-term mortality prediction, both the EuroScore and the STS-PROM score have been shown to predict mortality after cardiac surgery for up to 14 years.[32,33] Interestingly, the STS-PROM score performed nearly as well in predicting long-term survival after cardiac surgery compared to 30-day mortality.[33] In our TAVI patient cohort, the EuroScore II outperformed the logistic EuroScore and the STS-PROM score with regard to discriminatory power in prediction of cumulative mortality. Interestingly, the EuroScore II predicted long-term mortality almost as well as short-term mortality. To our knowledge, this is the first study comparing the EuroScore II to established scores in predicting long-term outcome in TAVI patients. Hence, the EuroScore II can be used to estimate the likelihood not only of short-term, but also of long-term survival. Besides the prediction of short-term mortality, the ability to predict long-term outcome after TAVI is important, and will even become more important with the aging of the population and the anticipated extension of transcatheter procedures to younger patients.

However, all currently available risk scores have substantial limitations. Predicted mortality varies considerably depending on the risk score utilized as different variables with diverse weighting are incorporated. All scores were derived from cardiac databases of patients undergoing cardiac surgery, mainly CABG, and both age and risk profile of patients undergoing cardiovascular procedures have changed considerably since the logistic EuroScore and the STS-PROM score have been established.[34] With regard to TAVI, patients evaluated for transcatheter procedures are somewhat different to those scheduled for heart surgery. Patients currently undergoing TAVI are a highly selected group of high-risk elderly patients with numerous comorbidities, and these risk characteristics were underrepresented in the patients in whom risk algorithms were established, and various additional variables such as liver disease, frailty, porcelain aorta, or previous radiotherapy are not included in current risk models. $[29,35,36]$ In line with previous studies, all three evaluated scores overall had suboptimal discriminatory power and calibration in the TAVI patient 
population.[29] In our opinion, a risk scoring system specifically developed for TAVI patients is imperative as it has the potential to 1) improve patient selection for transcatheter versus surgical procedures, and 2) enhance short- and long-term outcome prediction after TAVI. However, it is of utmost importance to emphasize the need for clinical assessment of patients preferably in a multidisciplinary Heart Team.

Limitations of this study are its single center design. However, comprehensive clinical data was available in all patients treated with both the Edwards SAPIEN and the Medtronic CoreValve prosthesis.

In conclusion, this study demonstrates that the EuroScore II is superior to both the logistic EuroScore and the STS-PROM score in predicting both short-term and cumulative long-term mortality in patients undergoing TAVI. Furthermore, this study emphasizes the specific need of a risk algorithm designed for TAVI patients, and the importance of a thorough clinical assessment which allows to choose an individualized strategy for each patient. 


\section{FUNDING SOURCES}

Barbara E. Stähli has partially been supported by grants of the Swiss National Research Foundation (Special Programme University Medicine: Grant Nr 33CM30-1241112/1 and 3100-068118.02/1). The authors have received honoraria and research grants from Medtronic, Tollochenaz, Switzerland, and Edwards Lifesciences, Nyon, Switzerland. 


\section{REFERENCES}

Nkomo VT, Gardin JM, Skelton TN, Gottdiener JS, Scott CG, Enriquez-Sarano M: Burden of valvular heart diseases: A population-based study. Lancet 2006;368:1005-1011.

2 Bach DS, Cimino N, Deeb GM: Unoperated patients with severe aortic stenosis. J Am Coll Cardiol 2007;50:2018-2019.

3 Leon MB, Kodali S, Williams M, Oz M, Smith C, Stewart A, Schwartz A, Collins M, Moses JW: Transcatheter aortic valve replacement in patients with critical aortic stenosis: Rationale, device descriptions, early clinical experiences, and perspectives. Semin Thorac Cardiovasc Surg 2006;18:165-174.

4 lung B, Cachier A, Baron G, Messika-Zeitoun D, Delahaye F, Tornos P, Gohlke-Barwolf C, Boersma E, Ravaud P, Vahanian A: Decision-making in elderly patients with severe aortic stenosis: Why are so many denied surgery? Eur Heart J 2005;26:2714-2720.

5 Bouma BJ, van Den Brink RB, van Der Meulen JH, Verheul HA, Cheriex EC, Hamer HP, Dekker E, Lie KI, Tijssen JG: To operate or not on elderly patients with aortic stenosis: The decision and its consequences. Heart 1999;82:143-148.

6 Kodali SK, Williams MR, Smith CR, Svensson LG, Webb JG, Makkar RR, Fontana GP, Dewey TM, Thourani VH, Pichard AD, Fischbein M, Szeto WY, Lim S, Greason KL, Teirstein PS, Malaisrie SC, Douglas PS, Hahn RT, Whisenant B, Zajarias A, Wang D, Akin JJ, Anderson WN, Leon MB: Two-year outcomes after transcatheter or surgical aortic-valve replacement. The New England journal of medicine 2012;366:1686-1695.

7 Leontyev S, Walther T, Borger MA, Lehmann S, Funkat AK, Rastan A, Kempfert J, Falk V, Mohr FW: Aortic valve replacement in octogenarians: Utility of risk stratification with euroscore. The Annals of thoracic surgery 2009;87:1440-1445.

8 Barili F, Pacini D, Capo A, Rasovic O, Grossi C, Alamanni F, Di Bartolomeo R, Parolari A: Does euroscore ii perform better than its original versions? A multicentre validation study. Eur Heart J 2013;34:22-29.

9 Biancari F, Vasques F, Mikkola R, Martin M, Lahtinen J, Heikkinen J: Validation of euroscore ii in patients undergoing coronary artery bypass surgery. The Annals of thoracic surgery 2012;93:1930-1935. 
Nashef SA, Roques F, Sharples LD, Nilsson J, Smith C, Goldstone AR, Lockowandt U: Euroscore II. Eur J Cardiothorac Surg 2012;41:734-744; discussion 744-735.

11 Wendt D, Osswald BR, Kayser K, Thielmann M, Tossios P, Massoudy P, Kamler M, Jakob $\mathrm{H}$ : Society of thoracic surgeons score is superior to the euroscore determining mortality in high risk patients undergoing isolated aortic valve replacement. The Annals of thoracic surgery 2009;88:468474; discussion 474-465.

12 Dewey TM, Brown D, Ryan WH, Herbert MA, Prince SL, Mack MJ: Reliability of risk algorithms in predicting early and late operative outcomes in high-risk patients undergoing aortic valve replacement. J Thorac Cardiovasc Surg 2008;135:180-187.

13 Ambler G, Omar RZ, Royston P, Kinsman R, Keogh BE, Taylor KM: Generic, simple risk stratification model for heart valve surgery. Circulation 2005;112:224-231.

14 Jin R, Grunkemeier GL, Starr A: Validation and refinement of mortality risk models for heart valve surgery. The Annals of thoracic surgery 2005;80:471-479.

15 Reid C, Billah B, Dinh D, Smith J, Skillington P, Yii M, Seevanayagam S, Mohajeri M, Shardey G: An australian risk prediction model for 30-day mortality after isolated coronary artery bypass: The ausscore. J Thorac Cardiovasc Surg 2009;138:904-910.

16 Geissler HJ, Holzl P, Marohl S, Kuhn-Regnier F, Mehlhorn U, Sudkamp M, de Vivie ER: Risk stratification in heart surgery: Comparison of six score systems. Eur J Cardiothorac Surg 2000;17:400-406.

17 Figulla L, Neumann A, Figulla HR, Kahlert P, Erbel R, Neumann T: Transcatheter aortic valve implantation: Evidence on safety and efficacy compared with medical therapy. A systematic review of current literature. Clin Res Cardiol 2011;100:265-276.

18 Haensig M, Holzhey DM, Borger MA, Schuler G, Shi W, Subramanian S, Rastan AJ, Mohr FW: Is the new euroscore II a better predictor for transapical aortic valve implantation? Eur J Cardiothorac Surg 2013

19 Goetzenich A, Deppe I, Schnoring H, Gafencu GL, Gafencu DA, Yildirim H, Tewarie L, Spillner J, Moza A: Euroscore 2 for identification of patients for transapical aortic valve replacement-a single center retrospective in 206 patients. J Cardiothorac Surg 2012;7:89.

20 Watanabe Y, Hayashida K, Lefevre T, Chevalier B, Hovasse T, Romano M, Garot P, Farge A, Donzeau-Gouge P, Bouvier E, Cormier B, Morice MC: Is euroscore II better than euroscore in predicting mortality after transcatheter aortic valve implantation? Catheter Cardiovasc Interv 2012 
21 Durand E, Borz B, Godin M, Tron C, Litzler PY, Bessou JP, Dacher JN, Bauer F, Cribier A, Eltchaninoff $\mathrm{H}$ : Performance analysis of euroscore II compared to the original logistic euroscore and sts scores for predicting 30-day mortality after transcatheter aortic valve replacement. Am J Cardiol 2013

22 Stahli BE, Bunzli R, Grunenfelder J, Buhler I, Felix C, Bettex D, Biaggi P, Tanner FC, Nguyen-Kim DL, Plass A, Ge H, Falk V, Luscher TF, Corti R, Maier W, Altwegg LA: Transcatheter aortic valve implantation (tavi) outcome according to standardized endpoint definitions by the valve academic research consortium (varc). J Invasive Cardiol 2011;23:307-312.

23 Nashef SA, Roques F, Michel P, Gauducheau E, Lemeshow S, Salamon R: European system for cardiac operative risk evaluation (euroscore). Eur J Cardiothorac Surg 1999;16:9-13.

24 Hickey GL, Grant SW, Murphy GJ, Bhabra M, Pagano D, McAllister K, Buchan I, Bridgewater B: Dynamic trends in cardiac surgery: Why the logistic euroscore is no longer suitable for contemporary cardiac surgery and implications for future risk models. Eur J Cardiothorac Surg 2012

25 Ben-Dor I, Gaglia MA, Jr., Barbash IM, Maluenda G, Hauville C, Gonzalez MA, Sardi G, Laynez-Carnicero A, Torguson R, Okubagzi P, Xue Z, Goldstein SA, Suddath WO, Kent KM, Lindsay J, Satler LF, Pichard AD, Waksman R: Comparison between society of thoracic surgeons score and logistic euroscore for predicting mortality in patients referred for transcatheter aortic valve implantation. Cardiovasc Revasc Med 2011;12:345-349.

26 Schenk S, Fritzsche D, Atoui R, Koertke H, Koerfer R, Eitz T: Euroscore-predicted mortality and surgical judgment for interventional aortic valve replacement. J Heart Valve Dis 2010;19:5-15.

27 Piazza N, Otten A, Schultz C, Onuma Y, Garcia-Garcia HM, Boersma E, de Jaegere P, Serruys PW: Adherence to patient selection criteria in patients undergoing transcatheter aortic valve implantation with the $18 f$ corevalve revalving system. Heart 2010;96:19-26.

28 Zahn R, Gerckens U, Grube E, Linke A, Sievert H, Eggebrecht H, Hambrecht R, Sack S, Hauptmann KE, Richardt G, Figulla HR, Senges J: Transcatheter aortic valve implantation: First results from a multi-centre real-world registry. Eur Heart J 2011;32:198-204.

29 Piazza N, Wenaweser P, van Gameren M, Pilgrim T, Tzikas A, Otten A, Nuis R, Onuma Y, Cheng JM, Kappetein AP, Boersma E, Juni P, de Jaegere P, Windecker S, Serruys PW: Relationship between the logistic euroscore and the society of thoracic surgeons predicted risk of 
mortality score in patients implanted with the corevalve revalving system--a bern-rotterdam study. Am Heart J 2010;159:323-329.

30 Di Dedda U, Pelissero G, Agnelli B, De Vincentiis C, Castelvecchio S, Ranucci M: Accuracy, calibration and clinical performance of the new euroscore II risk stratification system. Eur J Cardiothorac Surg 2013;43:27-32.

31 Chalmers J, Pullan M, Fabri B, McShane J, Shaw M, Mediratta N, Poullis M: Validation of euroscore II in a modern cohort of patients undergoing cardiac surgery. Eur J Cardiothorac Surg 2013;43:688-694.

32 Toumpoulis IK, Anagnostopoulos CE, Toumpoulis SK, DeRose JJ, Jr., Swistel DG: Euroscore predicts long-term mortality after heart valve surgery. The Annals of thoracic surgery 2005;79:1902-1908.

33 Puskas JD, Kilgo PD, Thourani VH, Lattouf OM, Chen E, Vega JD, Cooper W, Guyton RA, Halkos M: The society of thoracic surgeons 30-day predicted risk of mortality score also predicts long-term survival. The Annals of thoracic surgery 2012;93:26-33; discussion 33-25.

34 Frilling B, von Renteln-Kruse W, Riess FC: Evaluation of operative risk in elderly patients undergoing aortic valve replacement: The predictive value of operative risk scores. Cardiology 2010;116:213-218.

35 Thomas M, Schymik G, Walther T, Himbert D, Lefevre T, Treede H, Eggebrecht H, Rubino P, Colombo A, Lange R, Schwarz RR, Wendler O: One-year outcomes of cohort 1 in the edwards sapien aortic bioprosthesis european outcome (source) registry: The european registry of transcatheter aortic valve implantation using the edwards sapien valve. Circulation 2011;124:425433.

36 Sundermann S, Dademasch A, Praetorius J, Kempfert J, Dewey T, Falk V, Mohr FW, Walther T: Comprehensive assessment of frailty for elderly high-risk patients undergoing cardiac surgery. Eur J Cardiothorac Surg 2011;39:33-37. 


\section{FIGURE LEGENDS}

Table 1. Baseline characteristics.

LVEF indicates left ventricular ejection fraction, GFR glomerular filtration rate, and NYHA New York Heart Association, respectively. Results are presented as number and percentages or median and interquartile ranges. $P \leq 0.05$ denotes a significant difference between patients of the different EuroScore II groups.

Table 2. Risk quartiles of the EuroScore II, the logistic EuroScore, and the STS-PROM score.

Figure 1. Risk Scores in survivors (S) and non-survivors (NS) after transcatheter aortic valve implantation (TAVI). EuroScore II (A), logistic EuroScore (B), and STS-PROM score (C) in survivors (S) and non-survivors (NS) at 30 days. EuroScore II (D), logistic EuroScore (E), and STSPROM score (F) in survivors (S) and non-survivors (NS) at total follow-up. $P \leq 0.05$ denotes a significant difference between non-survivors and survivors.

Figure 2. Receiver operating characteristic $(\mathrm{ROC})$ curves for predicting 30-day mortality. ROC curve analysis showing the prognostic value of the EuroScore II (green, AUC: 0.70), the logistic EuroScore (blue, AUC: 0.61), and the STS-PROM score (orange, AUC: 0.59).

Figure 3. A. Low-risk, intermediate risk, and high-risk TAVI patients calculated by the

EuroScore II. A. According to calculated optimal cut-points for the EuroScore II, the patient cohort was devided into three groups: a low-risk group with an EuroScore $\leq 4 \%$ and a 30-day mortality of $1.2 \%$, an intermediate risk group with an EuroScore II between $4 \%$ and $9 \%$ and a 30 -day mortality of $8.6 \%$, and a high-risk group with an EuroScore II > $9 \%$ and a 30 -day mortality of $17.1 \%$, respectively $(p=0.03)$. B. The Cox proportional hazards model was used to estimate the hazard ratio and confidence intervals respectively to adjust for differing risk factor distributions between groups (intermediate risk group: $\mathrm{HR} 2.1,95 \% \mathrm{Cl} 0.99-4.44, \mathrm{p}=0.05$; high-risk group: $\mathrm{HR} 2.87,95 \% \mathrm{Cl} 1.38$ 5.97, $p=0.005)$. 
Figure 1

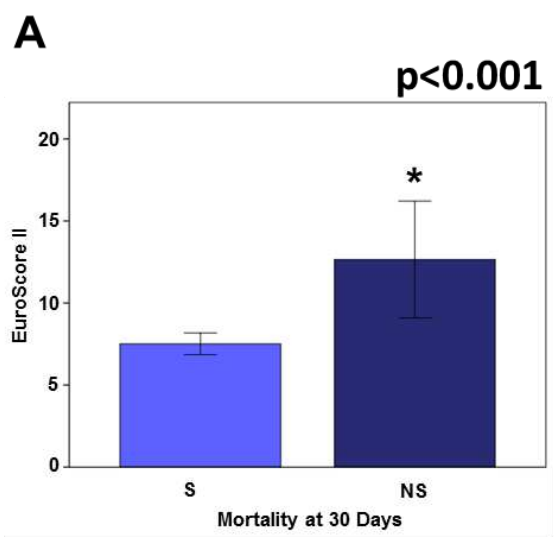

B
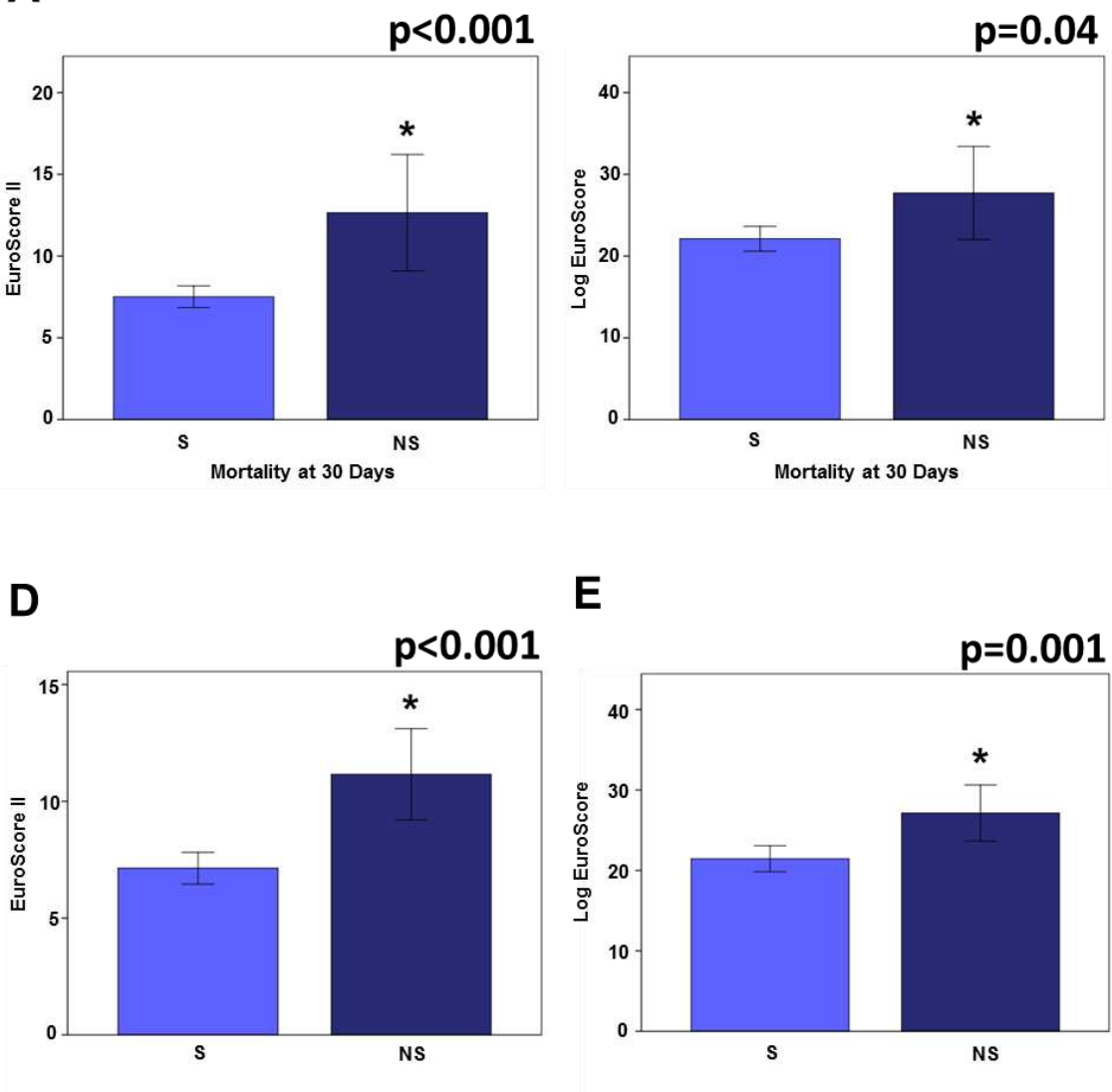

D

Mortality at Total Follow-up
E

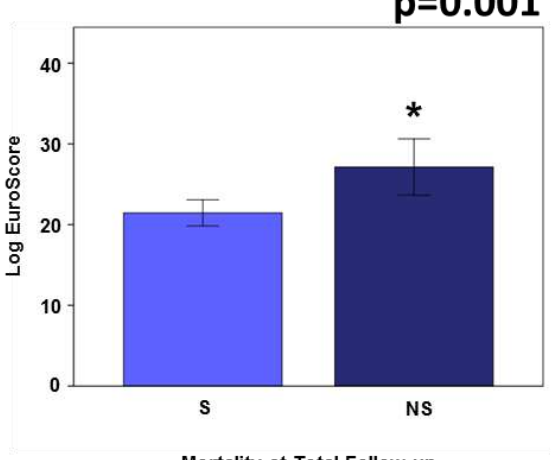

C

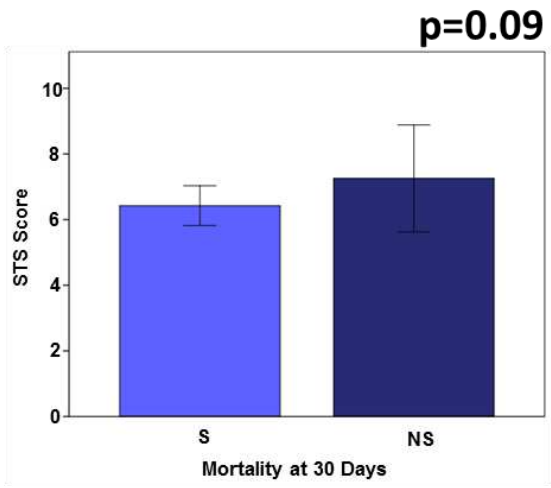

$\mathbf{F}$

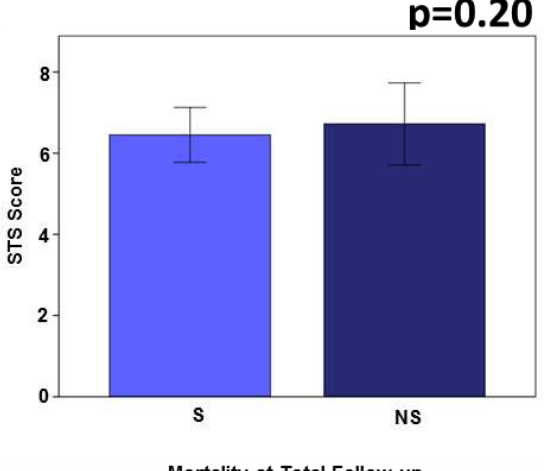


Figure 2

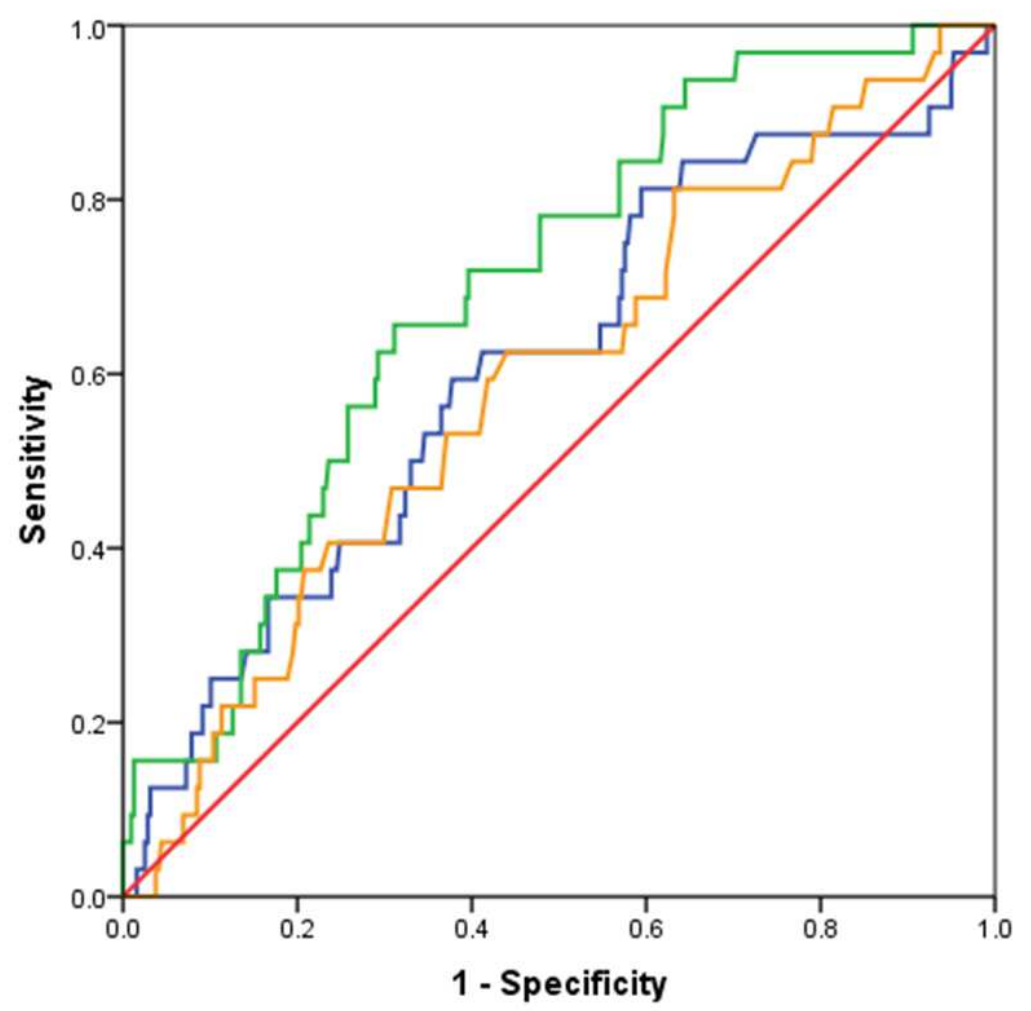


Figure 3

A

B
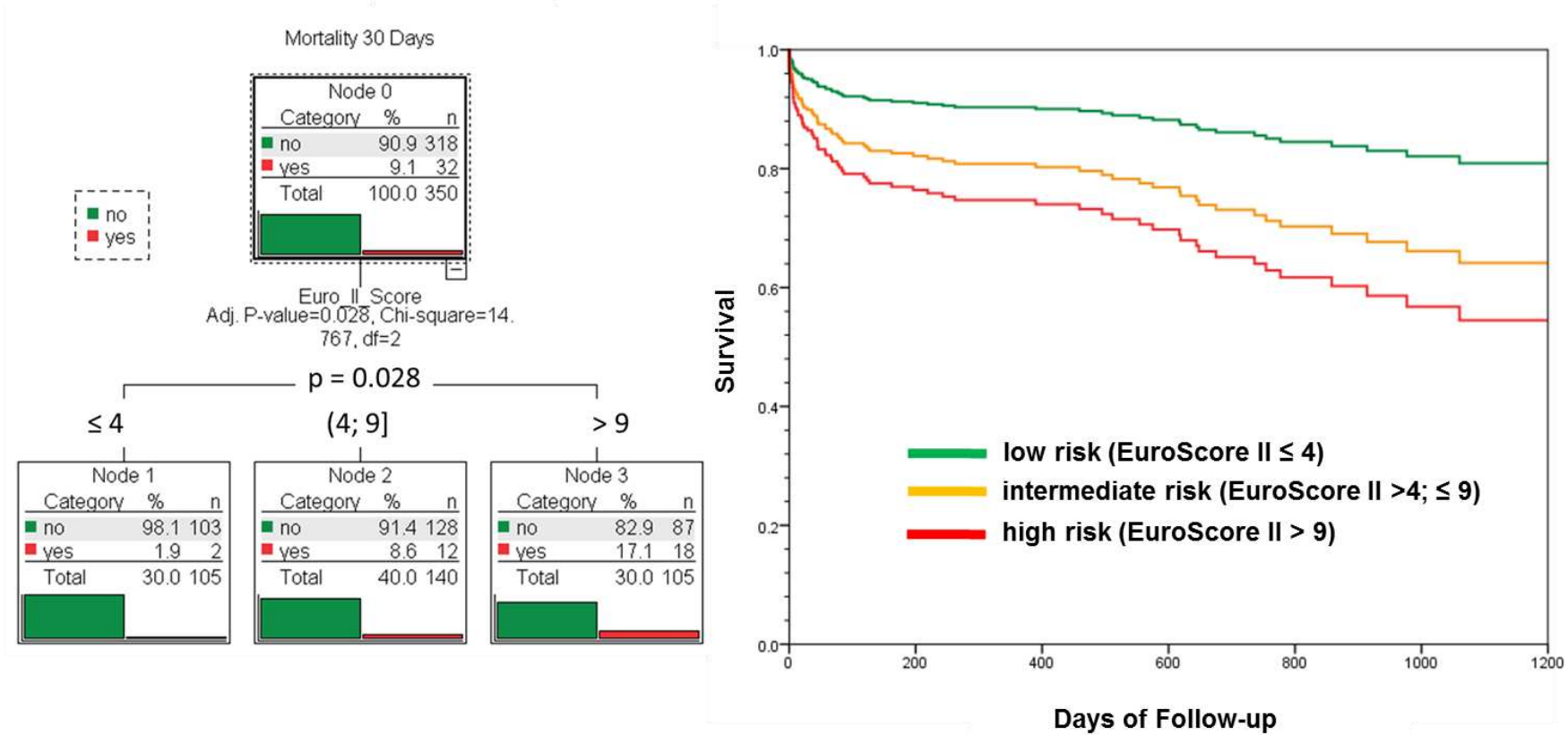
Table 1.

\begin{tabular}{|c|c|c|c|c|}
\hline Baseline Characteristics & \multicolumn{3}{|c|}{ Euroscore II } & p-value \\
\hline Age, years & $84.0(79.6-84.0)$ & $84.0(81.0-88.0)$ & $82.0(78.0-85.3)$ & 0.004 \\
\hline Male & $54(51)$ & $60(44)$ & $57(52)$ & 0.42 \\
\hline Body mass index $\left(\mathrm{kg} / \mathrm{m}^{2}\right)$ & $24.9(22.5-28.8)$ & $26.5(23.5-29.4)$ & $26.0(23.6-29.7)$ & 0.13 \\
\hline \multicolumn{5}{|l|}{ Procedural characteristics } \\
\hline Edwards SAPIEN prosthesis & $51(49)$ & $54(40)$ & $53(48)$ & 0.16 \\
\hline Transapical access & $11(11)$ & $22(16)$ & $28(26)$ & 0.01 \\
\hline \multicolumn{5}{|l|}{ Personal history } \\
\hline Diabetes mellitus & $17(16)$ & $29(22)$ & $37(34)$ & 0.008 \\
\hline Hypertension & $73(70)$ & $102(76)$ & $91(83)$ & 0.08 \\
\hline Chronic obstructive pulmonary disease & $18(17)$ & $24(18)$ & $27(25)$ & 0.30 \\
\hline Peripheral vascular disease & $13(12)$ & $24(18)$ & $44(40)$ & $<0.001$ \\
\hline Cerebrovascular disease & $13(12)$ & $31(23)$ & $36(33)$ & 0.002 \\
\hline Coronary artery disease & $47(45)$ & $80(59)$ & $76(69)$ & 0.001 \\
\hline Renal failure (GFR $<60 \mathrm{ml} / \mathrm{min}$ ) & $58(55)$ & $93(69)$ & $78(71)$ & 0.03 \\
\hline Reduced LVEF $(<50 \%)$ & $15(14)$ & $39(29)$ & $50(46)$ & $<0.001$ \\
\hline \multicolumn{5}{|l|}{ Symptoms } \\
\hline NYHA class III and IV & $61(58)$ & $103(76)$ & $91(83)$ & $<0.001$ \\
\hline
\end{tabular}


Table 2.

\begin{tabular}{|l|c|c|c|}
\hline & Pt. at risk & $\begin{array}{c}\text { Observed } \\
\text { mortality (\%) }\end{array}$ & $\begin{array}{c}\text { Predicted } \\
\text { mortality (\%) }\end{array}$ \\
\hline Log EuroScore & & & \\
\hline 1st & 87 & 4.6 & $8.89 \pm 0.30$ \\
\hline 2nd & 88 & 9.1 & $15.89 \pm 0.24$ \\
\hline 3rd & 88 & 10.2 & $24.05 \pm 0.29$ \\
\hline $4^{\text {th }}$ & 87 & 12.6 & $41.75 \pm 1.35$ \\
\hline EuroScore II & & & \\
\hline 1st & 85 & 1.2 & $2.23 \pm 0.08$ \\
\hline 2nd & 91 & 8.8 & $4.62 \pm 0.08$ \\
\hline 3rd & 87 & 10.3 & $8.07 \pm 0.13$ \\
\hline $4^{\text {th }}$ & 87 & 16.1 & $17.04 \pm 0.70$ \\
\hline STS Score & & & \\
\hline 1st & 89 & 6.7 & $2.74 \pm 0.06$ \\
\hline 2nd & 87 & 6.9 & $4.20 \pm 0.04$ \\
\hline 3rd & 80 & 8.9 & $5.86 \pm 0.08$ \\
\hline $4^{\text {th }}$ & 84 & 14.3 & $13.55 \pm 0.75$ \\
\hline
\end{tabular}

